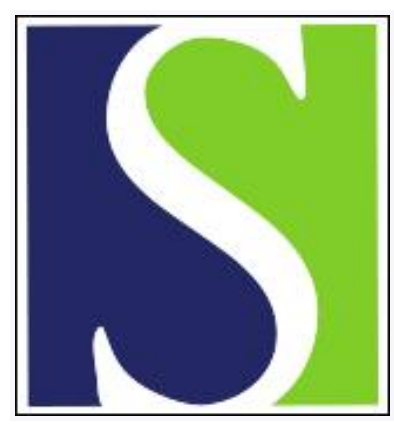

Scand J Work Environ Health 1997;23(3):221-226

https://doi.org/10.5271/sjweh.202

Issue date: Jun 1997

Coronary heart disease mortality among Newfoundland fluorspar miners

by Villeneuve PJ, Morrison HI

The following article refers to this text: 2010;36(5):373-383

Key terms: cohort study; healthy worker effect; occupational exposure; radon

This article in PubMed: www.ncbi.nlm.nih.gov/pubmed/9243733

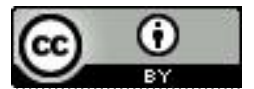




\title{
Coronary heart disease mortality among Newfoundland fluorspar miners
}

\author{
by Paul J Villeneuve, MSc, ${ }^{1}$ Howard I Morrison, $P h D^{2}$
}

\author{
Villeneuve PJ, Morrison HI. Coronary heart disease mortality among Newfoundland fluorspar miners. Scand $J$ \\ Work Environ Health 1997;23(2):221-6.
}

\begin{abstract}
Objectives The association between cumulative radon exposure and coronary heart disease mortality was studied in a retrospective cohort investigation of Newfoundland fluorspar miners.

Methods Multivariate Poisson regression techniques were used to estimate relative risks of coronary heart disease mortality by level of radon exposure. Relative risks (RR) were adjusted by attained age, calendar period, duration of exposure, and smoking status. Death from coronary heart disease was the outcome measure of interest and was identified by record linkage to the Canadian Mortality Database.

Results An elevated risk for mortality from coronary heart disease was observed among miners with a cumulative radon exposure exceeding 1000 working-level months [RR 1.5, 95\% confidence interval (95\% CI) $0.77-2.75]$. The association between radon exposure and coronary heart disease was not statistically significant according to a test for trend across exposure categories $(P=0.09)$. The smokers were 1.8 times more likely than the nonsmokers to die from coronary heart disease $(95 \%$ CI $1.1-2.8)$.

Conclusions These results suggest a positive association between coronary heart disease and radon exposure. However, these findings should be interpreted cautiously due to the inability to control for the confounding influence of other known risk factors of coronary heart disease.
\end{abstract}

Key terms cohort study, healthy worker effect, occupational exposure, radon.

It has been postulated that exposure to radiation may lead to the premature development of atherosclerosis and consequently to an increased risk of coronary heart disease (CHD). Evidence for this hypothesis comes from animal experiments (1), excess CHD deaths among women treated with radiation for breast cancer (2), and clinical reports of patients treated with radiotherapy who then developed premature atherosclerosis (3). An autopsy study which found increased alpha radiation in atherosclerotic plaques (4) and the monoclonal theory of atherosclerosis (5) provide further evidence for radiation being an etiologic factor for CHD.

The causal relationship between radiation exposure and cancer of the bronchus and lung has long been established (6). An excess risk of mortality from tuberculosis and other nonmalignant respiratory diseases has also been observed in several mining cohorts exposed to radon progeny (6). It is thought that most of these excess deaths are a consequence of exposure to silica (6). Excesses of cancers of the stomach (7-9), skin (10-11), buccal cavity, and pharynx (12) have also been observed in some radiation-exposed mining populations. However, a recent collaborative analysis of 11 mining cohorts suggest that the risk for cancers (other than lung) resulting from exposures to high concentrations of radon are negligible (13). Other possible adverse effects of radon exposure include chronic obstructive pulmonary disease, reproductive outcomes, and nonmalignant respiratory and renal diseases (14).

In populations of radiation-exposed miners, assessment of the dose-response relationship of lung cancer has been of primary interest, and analyses of possible CHD associations have often been neglected. Some of these studies have reported a decreased standardized mortality ratio (SMR) for CHD among miners when compared with that of the general population $(9,15-16)$. Conversely, an elevated SMR for CHD was found for a cohort of sulfide-ore miners exposed to radon (17).

The comparison of the mortality experience of an occupational cohort to the general population is biased by the healthy worker effect. Specifically, those who are healthy enough to work will be expected to have mortality rates that are less than that of the general population. The healthy worker effect produces lower mortality rates

1 Department of Preventive Medicine and Biostatistics, University of Toronto, Toronto, Ontario, Canada.

2 Laboratory Centre for Disease Control, Health Canada, Ottawa, Ontario, Canada.

Reprint requests to: Mr PJ Villeneuve, Department of Preventive Medicine and Biostatistics, University of Toronto, 12 Queens Park Crescent West, Toronto, Ontario, Canada M5S1A8. 
for several causes of death and may therefore mask real effects (18). The healthy worker effect is likely to be small for diseases that are unlikely to be present at the time of employment, diseases with symptoms that occur only a few years before death, and diseases whose risk factors have not been addressed in the selection process (19). Consequently, the healthy worker effect is likely to be small for lung cancer. The healthy worker effect is likely to be large for diseases that appear early in life and prevent participation in the labor force, diseases that have a long duration and interfere with employment at times when people are likely to be members of the work force, and diseases whose risk factors can be addressed in the selection process for entry and continuance in the work force (19). Therefore, the healthy worker effect is likely to be large for CHD, and, as such, the use of an SMR to evaluate the risk owing to radon exposure may not be appropriate.

This study examines the relationship between radon exposure and CHD in a cohort of Newfoundland fluorspar miners in which an excess of lung cancer from underground radon exposure had already been determined. Our analyses make use of an internal comparison group that represents a suitable means of controlling for the healthy worker effect (18).

\section{Subjects and methods}

\section{Study cohort}

The initial cohort consisted of 2111 underground miners and 550 surface workers employed by either the St Lawrence Fluorspar Company or by Newfoundland Fluorspar Limited. The cohort members who lacked adequate personal identifying information or who had died before 1950 were dropped from the analysis. Most of those excluded from the analysis were short-term workers during World War II. The remaining 1772 underground

Table 1. Characteristics of the Newfoundland fluorspar miner cohort. (WLM = working-level months)

\begin{tabular}{lccc}
\hline Characteristic & $\begin{array}{c}\text { Percentage } \\
\text { of cohort }\end{array}$ & Mean & SE \\
\hline $\begin{array}{l}\text { Calendar period of } \\
\text { first employment }\end{array}$ & & & \\
$\quad<1940$ & 14.0 &. &. \\
$1940<1960$ & 47.5 & $\cdot$ & $\cdot$ \\
1960 or later & 38.5 & $\cdot$ & $\cdot$ \\
Smoking habit & & & \\
$\quad$ Never smoker & 6.5 &. &. \\
Former smoker & 17.6 & $\cdot$ & $\cdot$ \\
$\quad$ Current smoker & 34.5 & $\cdot$ & $\cdot$ \\
$\quad$ Unknown & 41.3 & $\cdot$ & $\cdot$ \\
Duration of exposure (years) & & 5.7 & 5.9 \\
Age at first exposure (years) & & 28.7 & 16.1 \\
Cumulative exposure (WLM) & & 379 & 799 \\
\hline
\end{tabular}

miners and 352 surface workers were those analyzed in the 1988 report (12). For this analysis, a further 28 underground miners and 31 surface workers who were born before 1900 and for whom no death information was available were dropped, as it was assumed that death data had been missed. The final cohort of miners included 1743 underground miners and 321 millers or surface workers. A profile of the characteristics of the mining cohort is presented in table 1 . This cohort consisted of men who were exposed to radon for an average of 5.7 years.

\section{Radon exposure assessment}

Estimates of working-level months according to year, mine, and occupation between 1933-1960 were provided by the Atomic Energy Control Board of Canada (20). These values were based on levels measured in 1960, a review of historical work conditions of the mine, and mine architecture. From 1960 to 1967 the average exposure was 0.5 working levels. One working level is defined as the concentration of short-lived radon daughters that gives rise to $1.3 \times 10^{5} \mathrm{MeV}$ of alpha radiation. From 1968 on, the radiation levels were measured more frequently. In 1969, daily exposures for each worker were recorded according to radiation levels in the workplace on a given day. Cumulative exposures were expressed in working-level months (WLM). One workinglevel month is equivalent to exposure to 1 working level for $170 \mathrm{~h}$ ).

\section{Smoking information}

A survey was conducted in 1993 to update previously collected data on the smoking habits of the fluorspar miner cohort. Previous surveys to ascertain smoking behavior were conducted in 1960, 1966, and 1970 in St Lawrence, Newfoundland, by Health and Welfare Canada and in 1978 by the Atomic Energy Control Board. Smoking status (current, former or never smoker) could be determined for $59 \%$ of the cohort.

\section{Mortality follow-up}

The vital status of the cohort members between 1926 and 1984 had previously been ascertained (12). The mortality experience of the cohort was updated to the end of 1990 by manually tracing all members of the cohort through the Canadian Mortality Database operated by Statistics Canada. The linkage was performed by employees who were blind as to the exposure status. Copies of microfilmed death certificates were obtained, and the underlying causes of death were coded according to the 8th revision of the International Classification of Diseases by the Nosology Reference Centre of Statistics Canada. As with previous analyses, persons not 
found were assumed to be alive for the purposes of the analysis.

CHD (8th revision of the International Classification of Diseases rubrics 410-414) was selected when listed as the underlying cause of death. Deaths from respiratory disease were classified using the 8th revision of the International Classification of Diseases rubrics $460-519$.

Mortality was analyzed from the beginning of 1950 to the end of 1990 . Mortality before 1950 was not examined to facilitate comparisons with previously published results. Furthermore, the quality of Newfoundland death certificates before 1950 precluded their use (12).

\section{Statistical analysis}

For each miner, person-years were accumulated from the date of first employment until death or the end of the study period, which was 31 December 1990. Poisson regression models were used to fit relative risk models using the software program EPICURE (21).

The person-years were cross-classified by various time-dependent factors. Attained age was categorized as $<45,45-<55,55-<65,65-<75$ and $\geq 75$ years. Per son-years were also cross-classified by the calendar periods $1950-<1965,1965-<1975$, and $\geq 1975$. For each miner, duration of exposure was categorized as $<10$, $10--<20$ and $\geq 20$ years. Cumulative exposure to radon was categorized into 5 groups as $0,0^{+}-<250,250-$ $<500,500-<1000$ and $\geq 1000$ working-level months.

The miners were classified as either smokers, nonsmokers, or workers with an unknown smoking status. Due to the low prevalence of never smokers in this population and because CHD risk falls relatively quickly upon smoking cessation to almost that of never smokers (22), never smokers were combined with former smokers to form the nonsmoking category. Smoking status was determined from the last interview for which smoking status was reported.

Dose rate was examined with the inclusion of a covariate representing duration of exposure into a model containing cumulative working-level months. If an elevated risk of CHD mortality was found by increasing duration of exposure, exposure to radon over a longer period of time would be suggested to be more harmful than an equivalent cumulative dose received over a shorter period. Conversely, a decreased risk of CHD mortality for longer periods of exposure would suggest that high levels of exposure a over shorter period of time may be more relevant.

With the use of a model analogous to that used by Lubin et al (23) to examine lung cancer, it was assumed that the CHD mortality rate, $r(x, z, w)$, depended on cumulative working-level months, $w$; covariates that described the background mortality rate, $x$; and a vector of covariates, $z$, that could modify the dose-response relationship.
In our example, the $x$ covariates included categories of period of exposure and attained age, while the $z$ covariates consisted of smoking status and duration of exposure. The relative risk model used was

$$
r(x, z, w)=r_{0}(x) \operatorname{RR}(z, w),
$$

where $r_{0}(x)$ represented the background CHD mortality rate. The background rate was modeled as $r_{0}(x)=$ $\exp (\alpha x)$, where $\alpha$ represented the parameter vector of the background covariates. In the same fashion, the relativerisk component of the model, $\operatorname{RR}(z, w)$, was modeled using an exponential term.

The model was refitted by substituting the mean dose in working-level months for each of the 5 categories of cumulative radon exposure. In other words, radon exposure was modeled as a continuous covariate. This procedure enabled the significance of a trend in risk to be assessed by comparing the deviances of the models with and without continuous working-level months. The likelihood ratio test statistic, which was based on the difference in the model deviances, was approximately distributed as a chi-square with 1 degree of freedom. The Pvalues that were used to assess the trend in risk by duration of exposure and smoking status were calculated in the same manner. However, the significance level of the test for trend in smoking is based only on those observations for which smoking status is known.

\section{Results}

Between 1950 and 1990, 199 CHD deaths were observed among the miners. The results of the regression analyses are presented in table 2. An increased risk of CHD mortality was observed among the miners with cumulative radon exposures above 500 working-level months, although there was no monotonic relationship between increasing risk and increasing exposure and the test for trend was not statistically significant $(\mathrm{P}=0.09)$. Miners exposed to a cumulative radon exposure of at least 1000 working-level months had a relative risk of 1.46 when compared with those with no exposure. Smoking status was a significant predictor of CHD mortality ( $\mathrm{P}=0.01)$ with smokers having a risk that was approximately 1.8 times that of nonsmokers. The interaction term for cumulative radon exposure and smoking status was not significant (results not shown). Finally, a decreased risk was observed with longer durations of exposure. When compared with those for workers exposed for less than 10 years, the relative risk of CHD mortality was 0.76 and 0.33 for those exposed for $10-<20$ and $\geq 20$ years, respectively. Although not statistically significant, there was the suggestion of an increased risk of fatal respiratory disease with radon exposure (table 3 ). 
Table 2. Poisson regression estimates of the relative riska for coronary heart disease (CHD) mortality among Newfoundland fluorspar miners, $1950-1990$. ( $R R=$ relative risk, $95 \% \mathrm{Cl}=95 \%$ contidence interval, $W \mathrm{LM}=$ working-level months)

\begin{tabular}{|c|c|c|c|c|c|}
\hline Covariate & $\begin{array}{l}\text { Person- } \\
\text { years }\end{array}$ & $\begin{array}{l}\text { CHD } \\
\text { deaths }\end{array}$ & $\mathrm{RR}$ & $95 \% \mathrm{Cl}$ & P-value \\
\hline \multicolumn{6}{|c|}{ Cumulative radon exposure } \\
\hline $\begin{array}{l}0 \text { WLM } \\
>0-250 \text { WLM } \\
250 \leq 500 \text { WLM } \\
500 \leq 1000 \text { WLM } \\
\geq 1000 \text { WLM }\end{array}$ & $\begin{array}{r}9463 \\
33592 \\
5624 \\
3400 \\
4948\end{array}$ & $\begin{array}{l}50 \\
85 \\
24 \\
18 \\
22\end{array}$ & $\begin{array}{l}1.0 \\
0.90 \\
1.12 \\
1.57 \\
1.46\end{array}$ & $\begin{array}{c}- \\
0.62-1.31 \\
0.68-1.86 \\
0.89-2.76 \\
0.77-2.75\end{array}$ & 0.09 \\
\hline \multicolumn{6}{|l|}{ Smoking status } \\
\hline $\begin{array}{l}\text { Nonsmoker } \\
\text { Smoker } \\
\text { Unknown }\end{array}$ & $\begin{array}{l}14261 \\
19153 \\
23613\end{array}$ & $\begin{array}{r}27 \\
58 \\
114\end{array}$ & $\begin{array}{l}1.0 \\
1.78 \\
1.42\end{array}$ & $\begin{array}{c}- \\
1.13-2.82 \\
0.91-2.22\end{array}$ & $0.01^{\circ}$ \\
\hline \multicolumn{6}{|l|}{ Duration of exposure } \\
\hline $\begin{array}{l}<10 \text { years } \\
10 \leq 20 \text { years } \\
\geq 20 \text { years }\end{array}$ & $\begin{array}{r}49422 \\
6369 \\
1236\end{array}$ & $\begin{array}{r}175 \\
21 \\
3\end{array}$ & $\begin{array}{l}1.0 \\
0.76 \\
0.33\end{array}$ & $\begin{array}{c}- \\
0.42-1.33 \\
0.10-1.10\end{array}$ & 0.05 \\
\hline
\end{tabular}

a Background $\mathrm{CHD}$ rates are adjusted for attained age and period.

b The $\mathrm{P}$-value for test for trend is based on the likelihood ratio test statistic with 1 degree of freedom which compares the models with and without the covariate measured on a continuous scale.

- Only those miners with known smoking status were included in this test of trend.

Table 3. Poisson regression estimates of the relative riska of respiratory disease mortality of Newfoundland fluorspar miners, 19501990. (RR = relative risk, $95 \% \mathrm{Cl}=95 \%$ confidence interval, $\mathrm{WLM}=$ working - level months)

\begin{tabular}{|c|c|c|c|c|c|}
\hline Covariate & $\begin{array}{l}\text { Person- } \\
\text { years }\end{array}$ & $\begin{array}{l}\text { Respiratory } \\
\text { deaths }\end{array}$ & $\mathrm{RR}$ & $95 \% \mathrm{Cl}$ & $P$-value ${ }^{b}$ \\
\hline \multicolumn{6}{|c|}{ Cumulative radon exposure } \\
\hline $\begin{array}{l}0 \text { WLM } \\
>0-250 \text { WLM } \\
250 \leq 500 \text { WLM } \\
500 \leq 1000 \text { WLM } \\
\geq 1000 \text { WLM }\end{array}$ & $\begin{array}{r}9463 \\
33592 \\
5624 \\
3400 \\
4948\end{array}$ & $\begin{array}{r}8 \\
19 \\
8 \\
5 \\
8\end{array}$ & $\begin{array}{l}1.0 \\
1.04 \\
1.71 \\
1.72 \\
1.24\end{array}$ & $\begin{array}{l}-43-2.51 \\
0.43-4.86 \\
0.51-5.82 \\
0.36-4.29\end{array}$ & 0.80 \\
\hline \multicolumn{6}{|l|}{ Smoking status } \\
\hline $\begin{array}{l}\text { Nonsmoker } \\
\text { Smoker } \\
\text { Unknown }\end{array}$ & $\begin{array}{l}14261 \\
19153 \\
23613\end{array}$ & $\begin{array}{r}9 \\
20 \\
19\end{array}$ & $\begin{array}{l}1.0 \\
1.86 \\
1.82\end{array}$ & $\begin{array}{c}- \\
0.84-4.10 \\
0.35-1.95\end{array}$ & $0.09 \mathrm{c}$ \\
\hline \multicolumn{6}{|l|}{ Duration of exposure } \\
\hline $\begin{array}{l}<10 \text { years } \\
10 \leq 20 \text { years } \\
\geq 20 \text { years }\end{array}$ & $\begin{array}{r}49422 \\
6369 \\
1236\end{array}$ & $\begin{array}{r}35 \\
9 \\
4\end{array}$ & $\begin{array}{l}1.0 \\
1.61 \\
2.18\end{array}$ & $\begin{array}{c}- \\
0.62-4.18 \\
0.68-7.02\end{array}$ & 0.18 \\
\hline
\end{tabular}

a The background rates for coronary heart disease were adjusted for attained age and period.

b The P-value for test for trend is based on the likelihood ratio test statistic with 1 degree of freedom which compares the models with and without the covariate measured on a continuous scale.

- Only those miners with known smoking status were included in this test of trend.

\section{Discussion}

The principal recipient of alpha irradiation from radon daughter products is the lung. However, radon can also be absorbed into the blood and longer lived decay products could potentially cause adverse effects at sites other than the lung (14). The actual dose delivered to other organs is dependent on the relative fraction of attached and free daughter products and on the size of the aerosol to which they are attached and on pulmonary function (24). Small amounts of alpha radiation in the arterial wall may cause subtle injuries to arterial structures and thus contribute to the development of atherosclerosis and consequently CHD (4).
If radiation exposure increases the risk of CHD mortality, an occupational group exposed to radon could have higher CHD mortality rates than the general population. Previous analyses of the same cohort over a shorter follow-up period yielded an SMR for diseases of the circulatory system that was 0.88 of that of the general Newfoundland population (12). This value is consistent with that of other studies of miners exposed to radon progeny $(9,15-16)$. An elevated SMR was found for a cohort of sulfide ore miners exposed to radon progeny (17). However, these miners were also exposed to several other CHD risk factors, including polycyclic aromatic hydrocarbons, nitroglycerin, noise, and stress. As previously detailed, the use of the SMR for CHD in these 
studies is likely to be heavily influenced by the healthy worker effect and, to a less extent, by the failure to identify all deaths among cohort members.

Unlike previous studies, our use of an internal comparison population largely removes the healthy worker effect. While it is conceivable that employees not healthy enough to work in the mines were assigned to surface work, they were still healthy enough to be employed. It is likely that surface workers resembled underground workers to a greater extent than did the entire male population of Newfoundland. Both surface workers and underground miners lived in the same locality, their smoking levels appeared comparable, and the socioeconomic status between the 2 groups, at least as indicated by wage scales, were fairly similar.

This study suggests that workers exposed to high levels of radon progeny have a greater risk of CHD mortality. Our analyses also revealed a decreased risk of CHD mortality among miners exposed to radon for a longer period, after control for cumulative radon exposure. Conversely, for lung cancer an inverse dose-rate effect has been noted with radon exposure and lung cancer risk (25). In other words, the risk of lung cancer is greater among those exposed to radon over a long period than among those exposed to an equivalent lifetime dose over a shorter period. For CHD, it is possible that, for fixed cumulative dose, shorter duration of exposure at a high rate may be more harmful than a longer duration of exposure at low rates. Alternatively, and especially for cardiovascular disease, miners who were employed for a longer duration may have been more healthy and at a reduced risk of developing CHD than those employed over a shorter period of time when the exposure levels to radon progeny may have been higher. Our finding should be interpreted cautiously due to the small number of CHD deaths that occurred in the upper 2 categories of exposure duration.

The potential for death linkages to be missed should have been modest based on the results of previous studies that have examined the completeness of the Canadian mortality data base and the record linkage process employed by Statistics Canada (26). It is unlikely that the deaths missed occurred in a systematic way that would have biased the results.

Numerous risk factors for CHD have been identified, and, as a result, these findings may be biased by the inability to adjust for their influence. Occupational factors that are associated with an increased risk of $\mathrm{CHD}$ include levels of physical activity, stress, shift work, noise, and temperature (27). Other risk factors include diabetes, obesity, cholesterol, triglyceride levels, and alcohol intake (28). The presented risk estimates were adjusted solely for age, period, and smoking status. Furthermore, residual confounding by smoking status may exist, as information was lacking for $41 \%$ of this cohort and because smoking status was modeled as a fixed rather than a time-dependent covariate.

Underground miners were also exposed to silica, diesel fumes, and other particulates and gases that may result in airflow obstruction or fibrosis. The relationship between the possible respiratory damage induced by these exposures and the subsequent development of CHD is unclear. Cumulative radon exposure was weakly associated in the current study with an increased risk of fatal respiratory diseases. Animals exposed to high levels of radon have an increased risk of emphysema and interstitial fibrosis (8). As well, because both radon and dust levels were dependent on ventilation rates, radon levels may be a surrogate measure for dust levels.

In this cohort, the mean exposure for underground miners was 378.6 working-level months over an average of 5.7 years of exposure. Although the current Canadian occupational standard of radon exposure is 4.0 workinglevel months (29), few workers are now exposed to anywhere near these levels. These analyses revealed a nonsignificant elevated risk of CHD mortality among miners exposed to very high concentrations of radon progeny. Nonetheless, the findings should be interpreted cautiously as the possible confounding influence of several factors could not be adequately assessed.

\section{Acknowledgments}

We would like to acknowledge the helpful suggestions of Dr Donald Wigle of Health Canada and Dr AB Miller of the University of Toronto. Martha Fair, Maureen Carpenter, and Kevin Buzdegan of Statistics Canada oversaw the record linkage portion of the study. We would also like to acknowledge the support of Marc Lupien and Eric Rabin of the Atomic Energy Control Board.

The record linkage and 1993 cigarette smoking survey portions of this study were sponsored by a contract from the Atomic Energy Control Board of Canada with Statistics Canada and Health Canada.

\section{References}

1. Sheehan JF. Foam cell plaques in the intima of irradiated small arteries. Arch Pathol 1944;37:297-308.

2. Rutqvist LE, Lax I, Fornander T, Johannson H. Cardiovascular mortality in a randomized trial of adjuvant radiation therapy versus surgery alone in primary breast cancer. Int I Radiat Oncol Biol Phys 1992;22(5):887-96.

3. Fajardo LF, Stewart JR, Cohen KE. Morphology of radiation induced cancer. Arch Pathol 1968;86:512-9.

4. Elkeles A. Alpha ray activity in coronary artery disease. J Am Geriatr Soc 1968;16:576-83.

5. Benditt EP. The origin of atherosclerosis. Sci Am 1977;236: 
74-85.

6. National Research Council. Committee on the biological effects of ionizing radiation: health risks and other internally deposited alpha-emitters. BEIR IV. Washington (DC): National Academy Press, 1988.

7. Muller J, Kusiak RA, Suranyi G, Ritchie AC. Study of mortality of Ontario gold miners, 1955-1957; part II. Toronto: Ontario Ministry of Labour, 1986.

8. Enterline PE. A review of mortality data for American coal miners. Ann NY Acad Sci 1972;200:260-72.

9. Timarche M, Pahphalen A, Allin F, Chameaud J, Bredon P. Mortality of a cohort of French uranium miners exposed to relatively low radon concentrations. Br J Cancer 1993;67: $1090-7$

10. Sevcova M, Seve J, Thomas J. Alpha radiation of the skin and the possibility of late effects. Health Phys 1978;35(6):803-6.

11. Waxweiler RJ, Roscoe RJ, Archer VE, Thun MJ, Wagoner JK, Lundin FE. Mortality follow-up through 1977 of the white underground uranium miners cohort examined by the United States Public Health Service. In: Gomez M, editor. Radiation hazards in mining: control, measurement and medical aspects, 823-830. New York (NY): Society of Mining Engineers of the American Institute of Mining, Metallurgical and Petroleum Engineers 1981.

12. Morrison HI, Semenciw RM, Mao Y, Wigle DT. Cancer mortality among a group of fluorspar miners exposed to radon progeny. Am J Epidemiol 1988;128:1266-75.

13. Darby SC, Whitley E, Howe GR, Hutchings SJ, Kusiak RA, Lubin JH, et al. Radon and cancers other than lung cancer in underground miners: a collaborative analysis of 11 studies. JNCI 1995:87(5):378-84.

14. Samet JM. Diseases of uranium miners and other underground miners exposed to radon [review]. Occup Med 1991;6(4): $629-39$.

15. Howe GR, Nair RC, Newcombe HB, Miller AB, Abbatt JD. Lung cancer mortality (1950-1980) in relation to radon daughter exposure in a cohort of workers at the Eldorado Beaverlodge uranium mine. JNCI 1986;77(2):357-62.

16. Roscoe RJ, Deddens JA, Salvan A, Schnorr TM. Mortality among Navajo uranium miners. Am J Public Health 1995; 85(4):535-40.

17. Ahlman K, Koskela R, Kuikka P, Koponen M, Annanmäki M. Mortality among sulfide ore miners. Am J Ind Med 1991;19: 603-17.

18. Breslow NE, Day NE. Statistical methods in cancer research; vol II (The design and analysis of cohort studies). Lyon: International Agency for Research on Cancer (IARC), 1987. IARC science publications, no 82 .
19. Choi BCK. Definition, sources, magnitude, effect modifiers and strategies of reduction of the healthy worker effect. J Occup Med 1992;34(10):979-88.

20. Corkhill DA, Dory AB. A retrospective study of radon daughter concentrations in the workplace in the fluorspar mines of St Lawrence, Nfld. Ottawa (Canada): Atomic Energy Control Board of Canada, 1984.

21. Hirosoft International Corporation. Epicure. Seattle (WA): Hirosoft International Corporation, 1988.

22. United States Department of Human and Health Services (USDHHS). The Health consequences of smoking: cardiovascular disease, a report of the Surgeon General, 1983. Rockville (MA): US Department of Human and Health Services, 1983.

23. Lubin JH, Boice JD, Edling C, Hornung RW, Howe G, Kunz E, et al. Radon and lung cancer risk: a joint analysis of 11 underground studies. Bethesda (MD): United States Department of Human and Health Services, 1994. NIH publication no, 94-3644.

24. United Nations Scientific Committee on the Effects of Atomic Radiation. Ionizing radiation: sources and biological effects, a 1982 report to the General Assembly. New York (NY): United Nations, 1982.

25. Lubin JH, Boice JD, Edling C, Hornung RW, Howe G, Kunz $\mathrm{E}$, et al. Radon-exposed underground miners and inverse doserate (protraction enhancement) effects. Health Phys 1995;69:494-500.

26. Shannon HS, Jamieson E, Walsh C, Julian JA, Fair ME, Buffet A. Comparison of individual follow-up and computerized linkage using the Canadian mortality database. Can $\mathbf{J}$ Public Health 1989;80:54-7.

27. Kristensen TS. Cardiovascular diseases and the work environment: a critical review of the epidemiologic literature on nonchemical factors. Scand J Work Environ Health 1989;15: 165-79.

28. Wilson PF. Established risk factors and coronary artery disease: The Framingham Study. Am J Hypertens 1994;7:7S$12 \mathrm{~S}$

29. Dory A. Practical difficulties related to implementation of ICRP-recommended dose limitation in uranium mines. In: Application of the dose limitation system for radiation protection: practical implications: proceedings of a topical seminar on the practical implications of the ICRP recommendations (1977) and the revised IAEA basic standards for radiation protection. Vienna: International Atomic Energy Agency, 1979.

Received for publication: 18 April 1996 